\title{
Quality of life and baseline characteristics associated with depressive symptoms among patients with heart disease
}

This article was published in the following Dove Press journal:

Clinical Epidemiology

23 July 2012

Number of times this article has been viewed

\author{
Sepehr Rejai' \\ Nicholas D Giardino \\ Sangeetha Krishnan ${ }^{1,3}$ \\ Ira S Ockene ${ }^{4}$ \\ Melvyn Rubenfire ${ }^{3}$ \\ Elizabeth A Jackson ${ }^{1,3}$ \\ 'Michigan Cardiovascular Research \\ and Reporting Program, ${ }^{2}$ Department \\ of Psychiatry, ${ }^{3}$ Department of Internal \\ Medicine, Division of Cardiovascular \\ Medicine, University of Michigan \\ Health System, Ann Arbor, Michigan, \\ USA; ${ }^{4}$ Division of Cardiovascular \\ Medicine, Department \\ of Internal Medicine, University \\ of Massachusetts Medical Center, \\ Worcester, MA, USA
}

\begin{abstract}
We sought to examine factors associated with depressive symptoms among patients with heart disease. Data from 197 patients admitted for coronary artery disease were examined using multivariate predictive models. Women and unmarried patients were more likely to report depressive symptoms. In multivariate models, we observed that depressive symptoms were associated with the level of tangible social (but not emotional) support, bodily pain, and vitality, but not the number of comorbidities, gender, or marital status.
\end{abstract}

Keywords: heart disease, quality of life, depression

\section{Introduction}

Among patients discharged after an acute coronary event (ACS), rates of depression are as high as $20 \%$ and $45 \%$. ${ }^{1,2}$ However, rates of depressive symptoms among patients recently discharged after cardiac procedures such as coronary angiography have not been well studied. Patients with depression are at increased risk for mortality, but are significantly less likely to enroll and complete cardiac rehabilitation, which has been shown to reduce recurrent infarction and all-cause mortality. ${ }^{2-6}$ Depressed patients show higher rates of nonadherence to medication and are less likely to commit to lifestyle, diet, and exercise modifications, putting them at an increased risk of mortality and future cardiovascular disease (CVD) events. ${ }^{7-9}$ Current guidelines for secondary prevention recommend assessment of cardiac patients for depression; however, many depressed patients go undiagnosed. ${ }^{10,11}$ Understanding specific factors associated with depression can assist clinicians in identifying patients at risk who may need screening for depression.

Using data from an observational study of recently hospitalized cardiac patients, we examined depressive symptoms and quality-of-life measures as well as clinical and demographic factors for those potentially associated with depressive symptoms among cardiac patients. We hypothesized that patients who reported lower levels of social support and poorer health function would be more likely to experience depression following admission for a cardiac event or procedure.

\section{Methods \\ Data source}

Patients admitted to the University of Massachusetts Health Center's University Hospital between September 2004 and October 2008 with diagnoses of acute coronary syndrome (ACS) or elective coronary angiogram, were eligible for study inclusion. 
Patients admitted for elective coronary angiography were excluded if they had no prior history of coronary artery disease (CAD), or if no significant CAD (defined as the presence of a coronary stenosis $\geq 50 \%$ stenosis in $\geq 1$ vessel) was found at the time of the angiogram. ACS was defined as unstable angina (UA), ST-segment elevation myocardial infarction (STEMI), or non-ST-segment elevation myocardial infarction (NSTEMI) using standard definitions. ${ }^{12}$

The diagnosis of ACS was defined by the presence of symptoms consistent with acute coronary insufficiency, increases in cardiac enzymes $(\mathrm{CK}-\mathrm{MB}>$ twice the upper limit of the hospital's normal range and/or positive troponin I), and/or positive acute electrocardiographic changes including: (1) transient ST-segment elevations of $\geq 1 \mathrm{~mm}$ in 2 or more contiguous leads, (2) ST-segment depressions of $\geq 1 \mathrm{~mm}$, (3) new T-wave inversions of $\geq 1 \mathrm{~mm}$, and (4) new left bundle branch block. ACS type and other eligibility criteria were based on review of medical records. Information on comorbidities including history of angina, myocardial infarction (MI), hyperlipidemia, diabetes mellitus (DM), hypertension, and prior stroke were also obtained through review of medical records. Patients were excluded if they lived outside of the Worcester metropolitan area, were unable to complete the baseline surveys, were nursing home residents, had a life expectancy of $<6$ months, or whose cardiac events were the result of trauma or bleeding.

Baseline demographic information including age, gender, and race/ethnicity were collected from patients during the index hospital information. Patients were also asked to complete the Becks Depression Index (BDI), version 1, ${ }^{13}$ the Medical Outcomes Study (MOS) Social Support questionnaire, ${ }^{14}$ and the 36-item short form (SF-36). ${ }^{15}$ The BDI comprises 21 questions, each of which has four possible scores, from $0-4 .{ }^{13}$ Scores for each item were added together for a total score. The study population was divided into two groups based on BDI score. Subjects were considered as having a low likelihood of depression if they scored between $0-9$ on the BDI, while those with a score of $\geq 10$ were considered as having depressive symptoms. A similar grouping by BDI $<9$ vs $\geq 10$ has been used in prior studies. ${ }^{16,17}$ Subgroup analyses were used to compare patients with moderate-to-severe depressive symptoms (BDI of $\geq 19$ ).

The MOS social support survey was designed to be a selfadministered survey which can assess multiple dimensions of social support among populations with chronic disease. ${ }^{14}$ The four domains of the survey are emotional/informational, tangible, affectionate, and positive social interaction. These domains have been tested and found to be reliable measures of social support which exhibit stability over time. The SF-36 has been used in many populations to survey health status, including those with CAD. This survey is comprised of eight domains, including physical functioning, role limitations due to physical health, role limitations due to emotional problems, vitality, emotional well-being, social functioning, bodily pain, and general health. For this analysis, we used the RAND (Research ANd Development) Group scoring system. ${ }^{18,19}$

The study personnel were trained to administer surveys and review medical records in a standardized format. Data were collected on standardized forms, and then forwarded to a database service for data entry after review for face validity. Data not within the set limit ranges, inconsistencies, and/or unrecorded fields were flagged and then returned for clarification and correction. All aspects of this study were approved by the Institutional Review Boards from the University of Massachusetts Medical School and the University of Michigan Health System. Informed consent was obtained from all patients.

Summary statistics are presented as frequencies and percentages or as means and standard deviations. Student's $t$-tests and chi-square tests were used to compare differences in the baseline physical and clinical characteristics between BDI groups. Analysis of variance was used to evaluate the differences between groups for domains of the SF-36. Logistic regression models were used to examine the differences in domains from the SF-36 and the MOS social support surveys, adjusting for clinical and baseline characteristics including age, sex, and marital status. Predictors of a BDI score of $\geq 10$, were explored using stepwise models which including all domains from both the SF-36 and the MOS surveys. Odds ratios were presented as point estimates, with 95\% lower and upper confidence limits and corresponding $P$ values. A $P$ value $<0.05$ was considered to be statistically significant. All analyses were performed using SAS software (v 9.1; SAS Institute Corp, Cary, NC).

\section{Results}

A total of 197 patients were included in this study, of which 97 patients scored $\geq 10$ on the BDI. Table 1 shows that patients with depressive symptoms were more likely to be female and unmarried. When comparing age, race, education level, or comorbidities, no differences were observed between patients who reported depressive symptoms and those who were asymptomatic. The prevalence of patients with BDI scores $\geq 10$ was similar among those discharged after ST elevation MI, non-ST elevation MI, and elective coronary angiography. 
Table I Baseline and clinical characteristics by BDI score among cardiac patients

\begin{tabular}{|c|c|c|c|}
\hline \multirow[t]{2}{*}{ Characteristics } & \multicolumn{3}{|c|}{ Participants } \\
\hline & $\begin{array}{l}\text { BDI }<10 \\
n=101\end{array}$ & $\begin{array}{l}\text { BDI } \geq 10 \\
n=97\end{array}$ & $P$ value \\
\hline Age, years, mean (SD) & $60.4(12.1)$ & $59.7(13)$ & 0.89 \\
\hline Male, n (\%) & $77(76.2)$ & $59(60.8)$ & 0.02 \\
\hline White ethnicity, n (\%) & $87(86.1)$ & $88(90.7)$ & 0.31 \\
\hline Married, n (\%) & $70(69.3)$ & $50(51.5)$ & 0.01 \\
\hline \multicolumn{4}{|l|}{ Education, n (\%) } \\
\hline No high school diploma & $16(15.8)$ & $16(16.5)$ & 0.90 \\
\hline $\begin{array}{l}\text { High school diploma } \\
\text { and/or some college }\end{array}$ & $56(55.4)$ & $62(63.9)$ & 0.23 \\
\hline $\begin{array}{l}\text { College diploma } \\
\text { and/or graduate degree }\end{array}$ & $26(25.7)$ & $18(18.6)$ & 0.22 \\
\hline \multicolumn{4}{|l|}{ Clinical factors, $n$ (\%) } \\
\hline Pre-existing heart disease ${ }^{\#}$ & $33(32.7)$ & $29(29.9)$ & 0.67 \\
\hline Diabetes mellitus & $14(13.9)$ & $20(20.6)$ & 0.21 \\
\hline Hypertension & $43(42.6)$ & $41(42.3)$ & 0.97 \\
\hline Hyperlipidemia & $48(47.5)$ & $37(38.1)$ & 0.18 \\
\hline \multicolumn{4}{|l|}{ Admission type, n (\%) } \\
\hline $\begin{array}{l}\text { ST elevation myocardial } \\
\text { infarction }\end{array}$ & $31(30.7)$ & $33(34)$ & 0.62 \\
\hline $\begin{array}{l}\text { Non-ST elevation } \\
\text { myocardial infarction } \\
\text { or unstable angina }\end{array}$ & $4 \mid(40.6)$ & $35(36.1)$ & 0.51 \\
\hline Elective angiography* & $28(27.7)$ & $29(29.9)$ & 0.74 \\
\hline
\end{tabular}

Notes: *Elective angiography with coronary stenosis $\geq 50 \%$ stenosis in $\geq \mathrm{I}$ vessels; \#pre-existing heart disease includes prior myocardial infarction, percutaneous coronary intervention, coronary artery bypass surgery, or hospitalization for angina.

Abbreviations: BDI, Beck Depression Index; SD, standard deviation.

We examined components of the MOS social support survey among those who reported any depressive symptoms compared to those who reported no depressive symptoms (Table 2). Patients who scored $\geq 10$ on the BDI were more likely to have lower scores for emotional or informational support, tangible support, and positive social support,

Table 2 Domains of social support (MOS) by BDI score among cardiac patients

\begin{tabular}{|c|c|c|c|}
\hline \multirow[t]{2}{*}{ Characteristics } & \multicolumn{3}{|c|}{ Participants } \\
\hline & $\begin{array}{l}\text { BDI }<10 \\
n=101\end{array}$ & $\begin{array}{l}\text { BDI } \geq 10 \\
\mathrm{n}=97\end{array}$ & $P$ value \\
\hline $\begin{array}{l}\text { Emotional/informational } \\
\text { support, mean (SD) }\end{array}$ & $34.7(0.66)$ & $32.4(0.93)$ & 0.046 \\
\hline $\begin{array}{l}\text { Tangible support, } \\
\text { mean (SD) }\end{array}$ & $18(0.31)$ & I6.7 (0.4I) & 0.02 \\
\hline $\begin{array}{l}\text { Affectionate support, } \\
\text { mean (SD) }\end{array}$ & I $3.4(0.26)$ & $12.6(0.37)$ & 0.06 \\
\hline $\begin{array}{l}\text { Positive social support, } \\
\text { mean (SD) }\end{array}$ & I $3.6(0.23)$ & $12.5(0.34)$ & 0.01 \\
\hline Total score, mean (SD) & $79.6(1.38)$ & $74.3(1.94)$ & 0.03 \\
\hline
\end{tabular}

Abbreviations: BDI, Beck Depression Index; MOS, Medical Outcomes Survey; $\mathrm{SD}$, standard deviation. compared to those who had a BDI $<10$. No difference was noted between the two groups for affectionate support. The total MOS social support survey score was lower for those who scored $\geq 10$ in the BDI compared to those who had a BDI score of below 10 (74.3 vs 79.6, $P=0.03$ ).

In terms of quality of life (QOL) measures, we examined the domains of the SF-36 by the BDI group (Table 3). Patients with depressive symptoms were more likely to report physical limitations compared to nondepressed patients. Patients who scored $\geq 10$ on the BDI scored lower on both the domains of physical function, and role limitations due to physical problems. A difference in reported bodily pain was also observed in patients who had depressive symptoms, these having a higher bodily pain score compared to those without depression (6.1 vs 4.5, $P<0.0001$ ). Differences were also observed for role limitations due to emotional problems ( 4.9 for those with a BDI $\geq 10$ vs 5.5 for those with a $\mathrm{BDI}<10, P<0.001)$. No statistically significant differences were observed for items related to general health perceptions, vitality, social functioning, and mental health.

To examine predictors of depressive symptoms in this population, we compared models incorporating factors from the SF-36 and MOS social support survey, which differed by BDI score.

In the model which included domains of the SF-36 in addition to baseline and clinical characteristics, bodily pain was associated with depressive symptoms defined as the groups with a BDI score $\geq 10$ (OR: $1.39,95 \%$ confidence interval [CI]: 1.16-1.68, $P<0.001)$. Being married reduced the odds

Table 3 Domains of functioning (SF-36) by BDI score among cardiac patients

\begin{tabular}{|c|c|c|c|}
\hline \multirow[t]{2}{*}{ Characteristics } & \multicolumn{3}{|c|}{ Participants } \\
\hline & $\begin{array}{l}\text { BDI }<10 \\
\mathbf{n}=\mathbf{I 0 I}\end{array}$ & $\begin{array}{l}\text { BDI } \geq 10 \\
n=97\end{array}$ & $P$ value \\
\hline $\begin{array}{l}\text { Physical functioning, } \\
\text { mean (SD) }\end{array}$ & $24.7(0.6 I)$ & $22.7(0.63)$ & 0.02 \\
\hline $\begin{array}{l}\text { Role limitations due } \\
\text { to physical problems, } \\
\text { mean (SD) }\end{array}$ & $6.6(0.17)$ & $6.1(0.2)$ & 0.04 \\
\hline Bodily pain, mean (SD) & $4.5(0.21)$ & $6.1(0.23)$ & $<0.0001$ \\
\hline $\begin{array}{l}\text { General health } \\
\text { perceptions, mean (SD) }\end{array}$ & I $6.5(0.32)$ & $16.6(0.39)$ & 0.90 \\
\hline Vitality, mean (SD) & I4.7 (0.3) & $14.4(0.22)$ & 0.33 \\
\hline $\begin{array}{l}\text { Social functioning, } \\
\text { mean (SD) }\end{array}$ & $5.5(0.17)$ & $5.8(0.14)$ & 0.23 \\
\hline $\begin{array}{l}\text { Role limitations due } \\
\text { to emotional problems, } \\
\text { mean (SD) }\end{array}$ & $5.5(0.11)$ & $4.9(0.15)$ & 0.001 \\
\hline Mental health, mean (SD) & $19.6(0.37)$ & $18.5(0.45)$ & 0.07 \\
\hline
\end{tabular}

Abbreviations: BDI, Beck Depression Index; SD, standard deviation. 
Table 4 Predictors of a BDI score $\geq 10$ among cardiac patients

\begin{tabular}{llll}
\hline Predictors & $\begin{array}{l}\text { Odds } \\
\text { ratio }\end{array}$ & $\begin{array}{l}\text { 95\% confidence } \\
\text { interval }\end{array}$ & P value \\
\hline Tangible support & 0.84 & $0.75-0.94$ & 0.003 \\
Bodily pain & 1.43 & $1.22-1.69$ & $<0.0001$ \\
Vitality & 0.85 & $0.75-0.98$ & 0.03 \\
Mental health & 0.90 & $0.82-0.99$ & 0.03 \\
\hline
\end{tabular}

Abbreviation: BDI, Beck Depression Index.

of a BDI score $\geq 10$ (OR: $0.44,95 \%$ CI: $0.22-0.88, P=0.02$ ). When adding all the components of the MOS social support survey to the model, tangible support, vitality, and bodily pain scores were significant predictors of differences in BDI groups (ie, reporting depressive symptoms or not). When sex and marital status were added to the model, the MOS social support factors were no longer statistically significant; while female sex appeared to increase the odds of reporting depressive symptoms (OR: $2.11,95 \%$ CI: $1.08-4.12, P=0.03$ ). A trend towards decreased odds of a BDI score of $\geq 10$ was observed in those who were married, which was not statistically significant (OR: $0.65,95 \%$ CI: $0.34-1.23, P=0.18$ ). Combining the factors from both the MOS social support survey and the SF-36 in a stepwise prediction model, we found that only four factors, namely tangible support, bodily pain, vitality, and mental health were significant predictors of reporting depressive symptoms, defined as a BDI score of $\geq 10$ (Table 4).

\section{Discussion}

Using a survey of cardiac patients admitted to a major teaching hospital, we observed that women were at increased risk of depressive symptoms after cardiac hospitalization. Other factors associated with depressive symptoms included not being married, not having tangible support at home, and bodily pain.

Depressive symptoms among cardiac patients are highly prevalent. In our study we observed that almost $50 \%$ of patients had mild-to-moderate depression based on the BDI scores. In one study of 887 patients who had experienced an MI, 32\% had mild-to-moderate depression. ${ }^{16}$ That particular study used the same BDI scores as the present analysis. A second study of heart failure patients also using the BDI observed that over $50 \%$ of the cohort reported mild-to-moderate depression. ${ }^{17}$ As with our study, this heart failure study observed an association between depressive symptoms and role limitations. Other studies have observed lower rates of depression among cardiac patients. ${ }^{18,19}$ It is likely that the difference in the prevalence of depression in various studies is due to differences in study populations as well as the screening instruments used to detect depressive symptoms.
Despite the high prevalence of major depression among cardiac patients, this comorbidity is frequently undiagnosed and untreated. ${ }^{20,21}$ Barriers to treatment include the overlap of depressive symptoms with those of CAD, the misconception that depression after an MI is expected and acceptable, and the lack of time and financial incentive for providers. ${ }^{22}$ Factors which may increase a cardiac patient's risk for depression are often not assessed or recognized by cardiologists. Ongoing evaluation of these factors is needed to address the effect of mental health on cardiac pathology.

To improve functionality and QOL in depressed patients with CAD, it is important to study components of psychological, emotional, and social support, in addition to the strictly physical dimensions of heart disease. We observed that patients with less social support or limitations due to physical or emotional problems were at increased risk of depression. These results are consistent with other studies in this population and reflect the importance of recognizing social support as an integral part of the patient's psychosocial profile, improvement in which has been shown to decrease depression, and may have a positive effect on QOL and reduce morbidity. ${ }^{25-27}$ In the study by Frasure-Smith et al, of the 887 patients discharged after MI, over a follow-up of 1 year, BDI scores were positively associated with cardiac mortality. ${ }^{16}$ This relationship was modified by social support, such that patients who reported higher levels of social support demonstrated less of a relationship between depression and cardiac mortality. In addition, patients who demonstrated improvements in depressive symptoms were also more likely to report higher levels of social support.

We observed that several QOL factors including social support were predictors of depressive symptoms in patients with CAD. Specifically, SF-36 measures of tangible support, vitality, and bodily pain may assist clinicians in recognizing patients who are at increased risk of depression. This and other studies using the SF-36 form have shown that patients' QOL and physical functioning are significantly reduced, post MI. Recognizing the high prevalence and detrimental effects of cardiac disease on lifestyle, functionality, and role limitations validates focusing more attention toward the broader aspects of health and more formal assessments of QOL. ${ }^{28,29}$

Several limitations existed in the current study's parameters. As a cross-sectional examination of cardiac patients at one institution, these results may not directly apply to other patients or hospitals. Potential biases - including selection bias - may exist, which further limit the generalizability of our findings. Finally, due to the nature of collecting follow-up information after 6 months, data from a number of patients were lost in the process. 


\section{Conclusion}

The effect of depression on CAD and its negative prognostic implications on morbidity and mortality have been extensively studied and are well established. ${ }^{30,31}$ Given both the negative prognostic value and high prevalence of depression among cardiac patients, improving cardiac care warrants a better understanding of depression predictors as well as differences between depressed and nondepressed patients. Factors such as patients' social support, physical functioning, bodily pain, and gender seem to differ among the two groups. Differences in these domains can be the target of clinical attention and screening and are areas in need of further study.

\section{Disclosure}

The authors report no conflicts of interest in this work.

\section{References}

1. Wenger NK. Current status of cardiac rehabilitation. J Am Coll Cardiol. 2008;51(17):1619-1631.

2. Lesperance F, Frasure-Smith N. Depression in patients with cardiac disease: a practical review. J Psychosom Res. 2000;48(4-5):379-391.

3. Zellweger MJ, Hachamovitch R, Kang X, et al. Prognostic relevance of symptoms versus objective evidence of coronary artery disease in diabetic patients. Eur Heart J. 2004;25(7):543-550.

4. Caulin-Glaser T, Maciejewski PK, Snow R, LaLonde M, Mazure C. Depressive symptoms and sex affect completion rates and clinical outcomes in cardiac rehabilitation. Prev Cardiol. 2007;10(1):15-21.

5. Taylor RS, Brown A, Ebrahim S, et al. Exercise-based rehabilitation for patients with coronary heart disease: systematic review and meta-analysis of randomized controlled trials. Am J Med. 2004;116(10):682-692.

6. O’Connor GT, Buring JE, Yusuf S, et al. An overview of randomized trials of rehabilitation with exercise after myocardial infarction. Circulation. 1989;80(2):234-244.

7. Carney RM, Freedland KE, Eisen SA, Rich MW, Jaffe AS. Major depression and medication adherence in elderly patients with coronary artery disease. Health Psychol. 1995;14(1):88-90.

8. Ziegelstein RC, Fauerbach JA, Stevens SS, Romanelli J, Richter DP, Bush DE. Patients with depression are less likely to follow recommendations to reduce cardiac risk during recovery from a myocardial infarction. Arch Intern Med. 2000;160(12):1818-1823.

9. Ariyo AA, Haan M, Tangen CM, et al; Cardiovascular Health Study Collaborative Research Group. Depressive symptoms and risks of coronary heart disease and mortality in elderly Americans. Circulation. 2000;102(15):1773-1779.

10. Balady GJ, Williams MA, Ades PA, et al. American Heart Association Exercise, Cardiac Rehabilitation, and Prevention Committee, the Council on Clinical Cardiology, American Heart Association Council on Cardiovascular Nursing, American Heart Association Council on Epidemiology and Prevention, American Heart Association Council on Nutrition, Physical Activity, and Metabolism, American Association of Cardiovascular and Pulmonary Rehabilitation. Core components of cardiac rehabilitation/secondary prevention programs: 2007 update: a scientific statement from the American Heart Association Exercise, Cardiac Rehabilitation, and Prevention Committee, the Council on Clinical Cardiology; the Councils on Cardiovascular Nursing, Epidemiology and Prevention, and Nutrition, Physical Activity, and Metabolism; and the American Association of Cardiovascular and Pulmonary Rehabilitation. Circulation. 2007;115(20):2675-2682.
11. Herridge ML, Stimler CE, Southard DR, King ML; AACV/PR Task Force. Depression screening in cardiac rehabilitation: AACVPR Task Force Report. J Cardiopulm Rehabil. 2005;25(1):11-13.

12. Latchamsetty R, Fang J, Kline-Rogers E, et al. Prognostic value of transient and sustained increase in in-hospital creatinine on outcomes of patients admitted with acute coronary syndrome. Am J Cardiol. 2007;99(7):939-942.

13. Beck AT, Ward CH, Mendelson M, Mock J, Erbaugh J. An inventory for measuring depression. Arch Gen Psychiatry. 1961;4:561-571.

14. Sherbourne CD, Stewart AL. The MOS social support survey. Soc Sci Med. 1991;32(6):705-714.

15. Ware JE Jr, Sherbourne CD. The MOS 36-item short-form health survey (SF-36). I. Conceptual framework and item selection. Med Care. 1992;30(6):473-483.

16. Frasure-Smith N, Lesperance F, Gravel G, et al. Social support, depression, and mortality during the first year after myocardial infarction. Circulation. 2000;101(16):1919-1924.

17. Freedland KE, Rich MW, Skala JA, Carney RM, Davila-Roman VG, Jaffe AS. Prevalence of depression in hospitalized patients with congestive heart failure. Psychosom Med. 2003;65(1):119-128.

18. Gonzalez MB, Snyderman TB, Colket JT, et al. Depression in patients with coronary artery disease. Depression. 1996;4(2):57-62.

19. Frasure-Smith N, Lesperance F, Talajic M. Depression following myocardial infarction. Impact on 6-month survival. JAMA. 1993;270(15):1819-1825.

20. Hinz A, Kittel J, Karoff M, Schwarz R. Age and sex dependencies of anxiety and depression in cardiologic patients compared with the general population. Psychosoc Med. 2004;1:Doc09.

21. Serrano CV Jr, Setani KT, Sakamoto E, AndreiAM, Fraguas R. Association between depression and development of coronary artery disease: pathophysiologic and diagnostic implications. Vasc Health Risk Manag. 2011;7:159-164.

22. Carney RM, Freedland KE, Sheline YI, Weiss ES. Depression and coronary heart disease: a review for cardiologists. Clin Cardiol. 1997;20(3):196-200.

23. Brown N, Melville M, Gray D, et al. Quality of life four years after acute myocardial infarction: short form 36 scores compared with a normal population. Heart. 1999;81(4):352-358.

24. Milani RV, Lavie CJ, Cassidy MM. Effects of cardiac rehabilitation and exercise training programs on depression in patients after major coronary events. Am Heart J. 1996;132(4):726-732.

25. Penninx BW, Beekman AT, Honig A, et al. Depression and cardiac mortality: results from a community-based longitudinal study. Arch Gen Psychiatry. 2001;58(3):221-227.

26. Barefoot JC, Helms MJ, Mark DB, et al. Depression and long-term mortality risk in patients with coronary artery disease. Am J Cardiol. 1996;78(6):613-617.

27. Brummett BH, Babyak MA, Barefoot JC, et al. Social support and hostility as predictors of depressive symptoms in cardiac patients one month after hospitalization: a prospective study. Psychosom Med. Nov-Dec 1998;60(6):707-713.

28. Brown N, Melville M, Gray D, et al. Quality of life four years after acute myocardial infarction: short form 36 scores compared with a normal population. Heart. Apr 1999;81(4):352-358.

29. Milani RV, Lavie CJ, Cassidy MM. Effects of cardiac rehabilitation and exercise training programs on depression in patients after major coronary events. Am Heart J. Oct 1996;132(4):726-732.

30. Penninx BW, Beekman AT, Honig A, et al. Depression and cardiac mortality: results from a community-based longitudinal study. Arch Gen Psychiatry. Mar 2001;58(3):221-227.

31. Barefoot JC, Helms MJ, Mark DB, et al. Depression and long-term mortality risk in patients with coronary artery disease. Am J Cardiol. Sep 15 1996;78(6):613-617. 


\section{Publish your work in this journal}

Clinical Epidemiology is an international, peer-reviewed, open access journal focusing on disease and drug epidemiology, identification of risk factors and screening procedures to develop optimal preventative initiatives and programs. Specific topics include: diagnosis, prognosis, treatment, screening, prevention, risk factor modification, systematic

Submit your manuscript here: http://www.dovepress.com/clinical-epidemiology-journal reviews, risk \& safety of medical interventions, epidemiology \& biostatical methods, evaluation of guidelines, translational medicine, health policies \& economic evaluations. The manuscript management system is completely online and includes a very quick and fair peer-review system, which is all easy to use. 